\title{
Biomimetic cementitious construction materials for next-generation infrastructure
}

\author{
Abir Al-Tabbaa \\ Professor of Geotechnical Engineering, University of Cambridge, \\ Cambridge, UK (corresponding author: aa22@cam.ac.uk) \\ Bob Lark \\ Emeritus Professor of Civil Engineering, Cardiff University, Cardiff, UK \\ Kevin Paine \\ Reader in Civil Engineering, University of Bath, Bath, UK \\ Tony Jefferson \\ Professor of Civil Engineering, Cardiff University, Cardiff, UK
}

\author{
Chrysoula Litina \\ Research Associate in Resilient Materials for Life Programme Grant, \\ University of Cambridge, Cambridge, UK \\ Diane Gardner \\ Senior Lecturer in Civil Engineering, Cardiff University, Cardiff, UK \\ Tim Embley \\ Group Innovation and Knowledge Manager, Costain Ltd, Maidenhead, UK
}

The resilience of civil engineering structures has traditionally been associated with the design of individual elements with sufficient capacity to respond appropriately to adverse events. This has traditionally employed 'robust' design procedures that focus on defining safety factors for individual adverse events and providing redundancy. As such, construction materials have traditionally been designed to specific technical specifications. Furthermore, material degradation is viewed as inevitable and mitigation necessitates expensive maintenance regimes. Based on a better understanding of natural biological systems, biomimetic materials that have the ability to adapt and respond to their environment have recently been developed. This fundamental change has the potential to facilitate the creation of a wide range of 'smart' materials and intelligent structures that can self-sense and self-repair without the need for external intervention which could transform infrastructure. This paper presents an overview of the development, application and commercial perspectives of a suite of complementary self-healing cementitious systems that have been developed as part of a national team and led to the first UK full-scale field trials on self-healing concrete.

\section{Introduction}

The UK's current ageing and deteriorating infrastructure is the result of decades of underinvestment that is now costing the nation $£ 2$ million/d (Kelly, 2014) and has resulted in the UK government heavily investing in both existing and new infrastructure, committing $\sim £ 500$ billion by 2020-2021 (HMT, 2016). Current figures show that half of the construction budget is being spent on the repair and maintenance of (mainly concrete) infrastructure at $£ 40$ billion/year (ONS, 2016). Moreover, the durability of repaired concrete structures continues to be a major concern as after 5 years, $20 \%$ of the repairs fail, increasing to $55 \%$ after 10 years (Tilly and Jacobs, 2007). Furthermore, these figures are compounded when the cost of disruptions and delays is considered, which could be up to ten-times that figure (Highways England, personal communication, 2018).

A major challenge is that civil engineering design practices remain traditional, based on the assignment of appropriate partial material and action factors and the provision of a degree of redundancy to prevent failure. Hence, construction materials are designed to meet a prescribed specification: material degradation is viewed as inevitable and mitigation necessitates expensive inspection, maintenance, repair and eventually replacement regimes. It is unsurprising, therefore, that poor material performance is the single main cause of deterioration and failure in infrastructure systems worldwide (Tilly and Jacobs, 2007).

These durability problems would be greatly diminished if construction materials could self-heal or mimic natural biological materials. These 'biomimetic' materials are advanced materials that can transform infrastructure by embedding resilience within its components and systems so that rather than being defined by individual events, they can evolve and adapt over their lifespan. Recent national and international governments and industry road mapping reports have highlighted that advanced infrastructure materials, with specific reference to biomimetic attributes, will play a pivotal role in the transition of infrastructure into a lowcarbon dioxide and resilient future (EC, 2014; GO-Science, 2017; i3P, 2017; WEF and BCG, 2016). This transition will necessitate a step change in the value placed on infrastructure materials and provide the much higher level of confidence needed in the reliability of the performance of infrastructure systems.

Most concrete infrastructure assets are regularly exposed to a myriad of damaging environmental actions, resulting in different forms of damage such as cracking, weakened areas of material, oxidation of reinforcement, loss of rebar cover, material dissolution, swelling and expansion. To date, the most extensively studied damage mode in cementitious systems, concrete being one example, is cracking. In this respect, self-healing phenomena in cementitious systems are broadly divided into two categories: autogenic and autonomic. Autogenic self-healing refers to self-healing processes that are an intrinsic characteristic of the components of the cementitious matrix, effective for small crack widths of $\leq 0 \cdot 15 \mathrm{~mm}$. In contrast, autonomic self-healing refers to actions that use components that do not naturally exist in the cementitious matrix - that is, 'engineered' additions - usually employed to deal with larger crack sizes. It is worth pointing out that self-healing phenomena would apply to all 
forms of damage listed earlier, but the focus of this paper is on cracking. A range of self-healing cementitious systems have been investigated by the research community and examples are shown schematically in Figure 1. For a detailed overview of the self-healing phenomena shown in Figure 1, see the publications by de Rooij et al. (2013) and De Belie et al. (2018). Different autogenic self-healing systems do work in a synergistic way. Similarly, autogenic and autonomic self-healing systems can potentially work in combination such that the autonomic system reduces the crack size and enables autogenic processes to complete the self-healing process. Ultimately, autonomic systems could be designed to work in tandem, which forms the basis of the work initiated in this paper.

The research presented in this paper was undertaken between 2013 and 2016 (Al-Tabbaa et al., 2017; Lark et al., 2013; Paine et al., 2015) as part of the Engineering and Physical Sciences Research Council-funded Materials for Life (M4L) project with the objectives of (a) developing a suite of complementary autonomic self-healing systems that can act for synergistic application to address physical damage (cracks) at a range of scales and $(b)$ demonstrating and implementing these self-healing systems in real applications. In particular, the research presented in this paper is focused on the work of the M4L research team to develop four self-healing systems: microcapsules, calcite-precipitating bacteria, shape memory polymers (SMPs) and vascular networks (Figure 1(b)). The specific

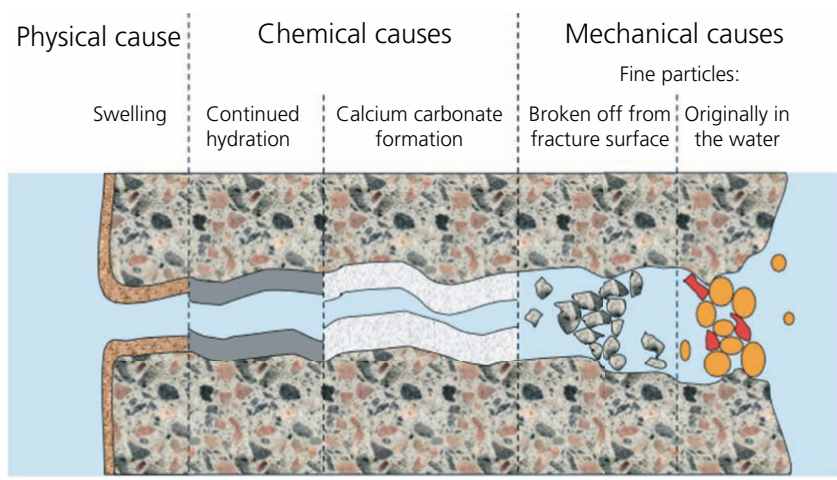

(a)

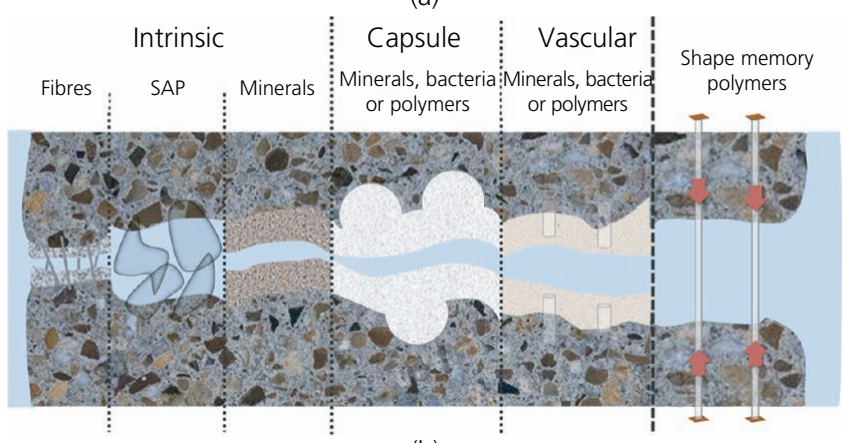

(b)

Figure 1. Self-healing phenomena in cementitious systems:

(a) autogenic self-healing (figure adopted from de Rooij et al. (2013)) and (b) autonomic self-healing (figure adapted from Souza (2017). SAP, superabsorbent polymers success and innovations in each case included the development of (a) microcapsules with switchable mechanical properties and with mineral healing cargo; $(b)$ bespoke combinations and microencapsulation of alkaliphilic bacteria, nutrients and precursors for rapid precipitation of healing products; (c) remotely activated SMP multistrand sheathed tendons; and $(d)$ innovatively created vascular networks using polyurethane tubing.

Subsequent sections of the paper provide a brief summary of the experimental laboratory work carried out to develop each of these four self-healing systems, including a summary of key findings, details of field tests undertaken in 2015 to validate the scaling up of those self-healing systems and to validate their performance using the A465 Highway development project as a case study. The paper concludes with an overview of a number of relevant commercial perspectives. This paper provides an overview of the M4L research and makes explicit reference to a number of other published outputs produced by M4L (Alazhari et al., 2018; Al-Tabbaa et al., 2017; Davies et al., 2015, 2016, 2018; De Belie et al., 2017; Gardner et al., 2012, 2014, 2017; Giannaros et al., 2016; Isaacs et al., 2013; Jefferson et al., 2010; Kanellopoulos et al., 2015, 2016, 2017; Lark et al., 2013; Litina, 2015; Paine et al., 2015, 2016; Pilegis et al., 2015; Qureshi, 2016; Sharma et al., 2017; Souza, 2017; Teall, 2017; Teall et al., 2017, 2018).

\section{Overview of the developed self-healing systems and associated laboratory work}

\subsection{Microcapsules}

These are micron-size capsules that contain a healing agent (cargo). Microcapsules rupture and release their healing agent when in the direct path of an approaching crack. The healing agent initiates chemical reactions which seal the crack. Microcapsules must rupture only when and where needed, not degrade prior to need; be capable of delivering sufficient quantity of an effective healing agent; and not undermine the structural integrity of the cementitious system. Two microencapsulation systems - namely, emulsification polymerisation and microfluidics - were set up to produce laboratory-scale quantities of microcapsules that enabled the production of a range of shells and cargo (Litina, 2015; Souza, 2017). While most research to date has focused on the use of epoxy cargo, the M4L work focused on the development of mineral-based cargo for better compatibility with the cementitious matrix and better shelf-life and handling. The most promising developments included microcapsules with polymeric gelatin/gum arabic shell and sodium silicate cargo (see Figure 2(a)), which was developed with an industry partner, Lambson, using complex coacervation and was upscaled for field trial applications (Kanellopoulos et al., 2017). These have a mean diameter of $300 \mu \mathrm{m}$ and are ductile, to survive the mixing initially, and then brittle within the hardened cement, to rupture under crack propagation.

The effective mixing and survivability of the microcapsules within the cementitious matrix was demonstrated with 
Biomimetic cementitious construction

materials for next-generation

infrastructure

Al-Tabbaa, Lark, Paine et al.

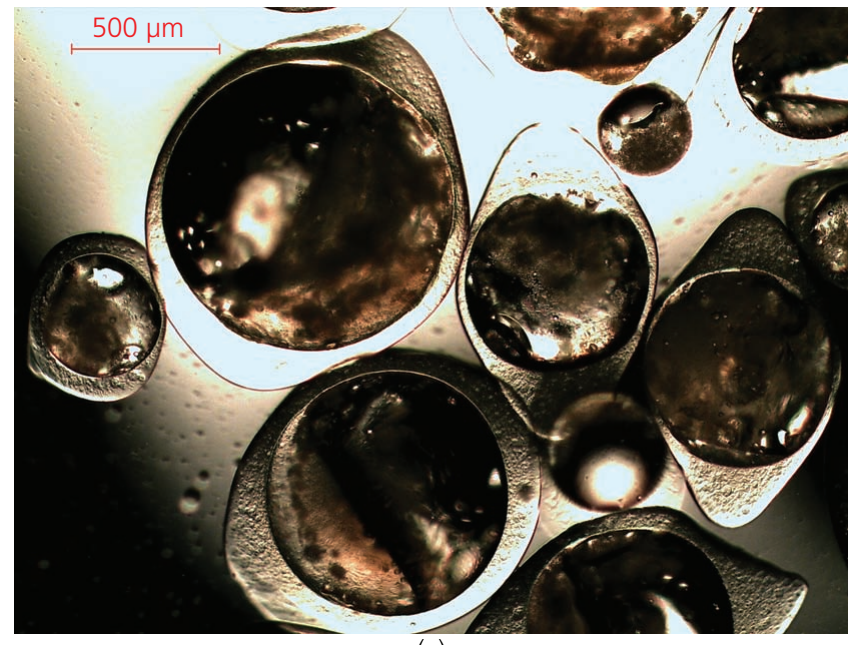

(a)

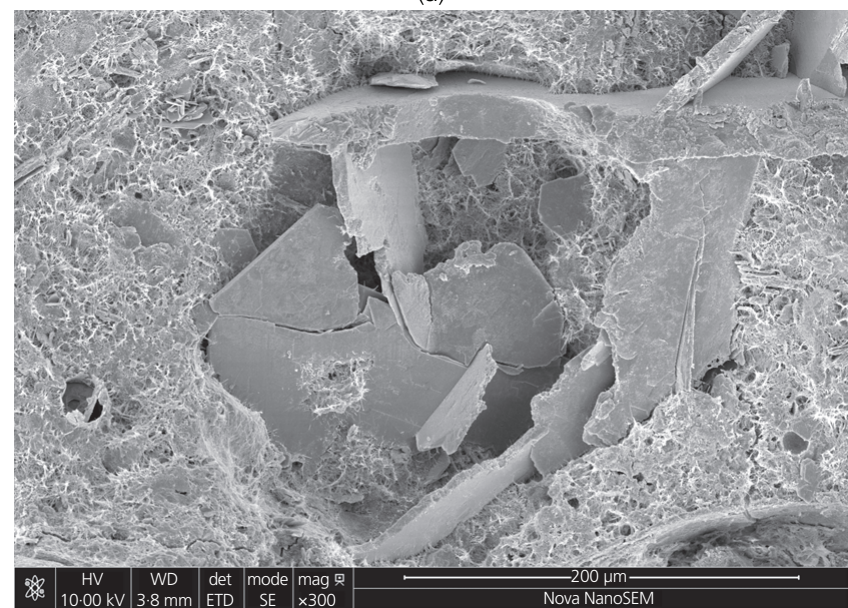

(c)

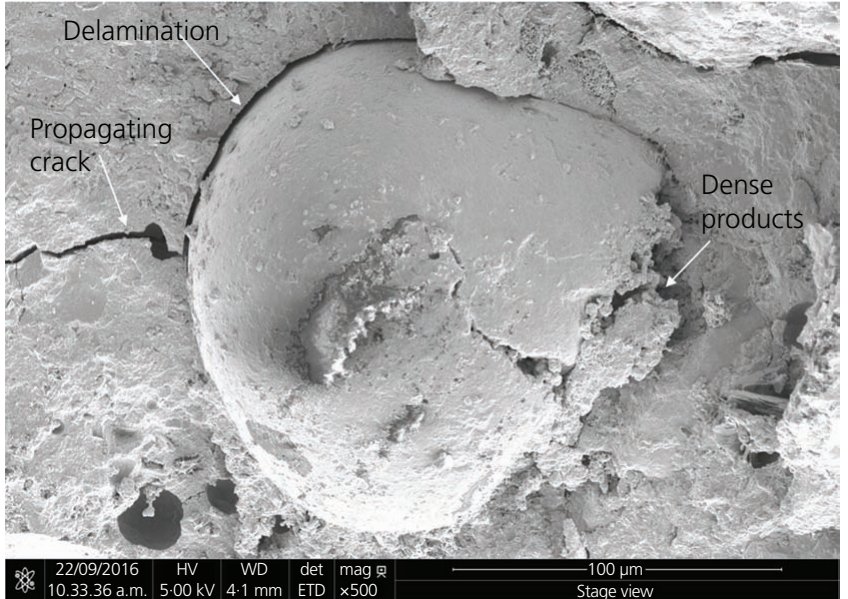

(b)

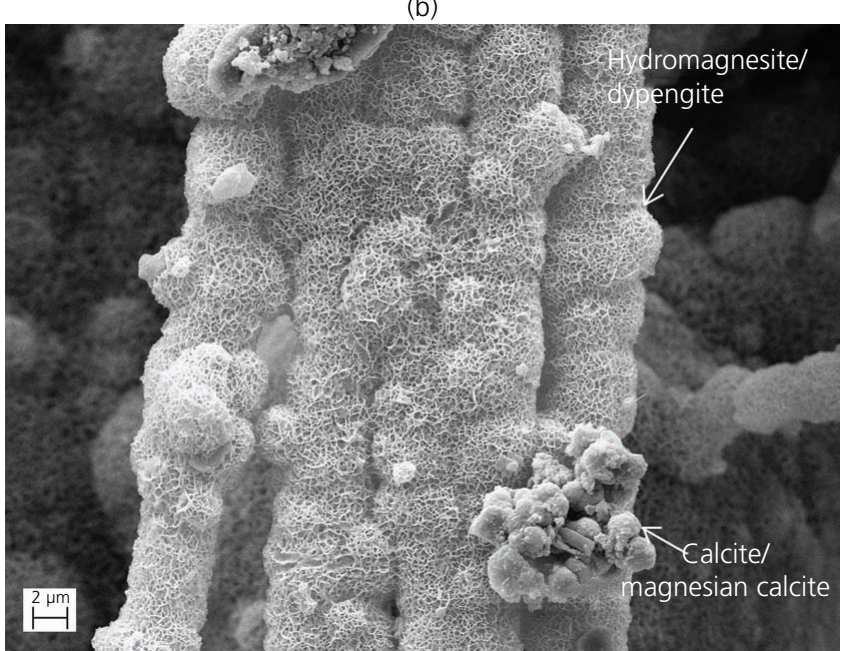

(d)

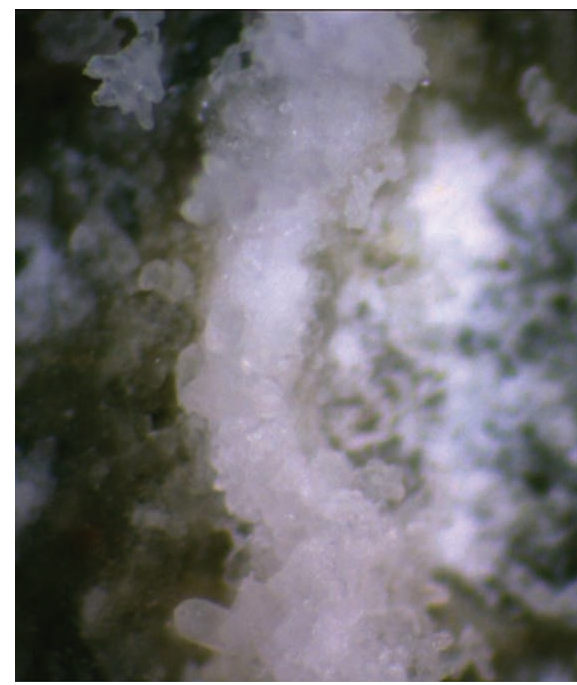

(e)

Figure 2. Self-healing microcapsules: (a) the microcapsules developed with Lambson for the field trials (Kanellopoulos et al., 2017); (b) the microcapsules embedded in cement (Giannaros, 2017); (c) a ruptured microcapsule with healing products (Kanellopoulos et al., 2017); (d) an example of a healing product scaffold (Qureshi, 2016); (e) crack healing in action (reproduced from Kanellopoulos et al. (2015), by kind permission of Elsevier) 
microstructural imaging (see Figure 2(b)). Extensive laboratory investigations were then carried out to investigate the effect of the polymeric microcapsules on the fresh and hardened properties of cementitious matrices (cement, mortar and/or concrete) (Kanellopoulos et al., 2016). Microcapsule dosages of up to $32 \%$ by volume $(10 \cdot 7 \% \mathrm{wt})$ were tested. Results showed that up to $8 \%$ by volume $(\sim 2 \cdot 7 \% \mathrm{wt})$ addition of these microcapsules to the cement had negligible detrimental effect on the workability and mechanical properties of the cementitious matrix. Optimisation studies in terms of the self-healing efficiency under different damage scenarios and underwater curing (Giannaros et al., 2016; Kanellopoulos et al., 2015) were also undertaken. Crack widths between $0 \cdot 11$ and $0 \cdot 25 \mathrm{~mm}$ were tested. Microstructural analyses, to understand the healing mechanisms, and mechanical testing and durability performance, using sorptivity and permeability, were carried out, as the common metrics for self-healing effectiveness (Ferrara et al., 2018). Scanning electron microscopy imaging confirmed the release of the sodium silicate cargo, which reacted with the cementitious matrix, producing an excess of hydration products (illustrated in Figure 2(c)), which sometimes formed a stable scaffold for the proliferation of carbonate crystals that deposited due to autogenic healing (illustrated in Figure 2(d)). This illustrated a new mechanism through which autonomic and autogenic self-healing interacted. Complete healing was observed after $28 \mathrm{~d}$ (illustrated in Figure 2(e)). A strong correlation between healing potential and microcapsule content was identified. Increased strength recovery compared to the control, with no microcapsules, $(\sim 25 \%)$, was observed. A reduction in sorptivity values compared to the control $(\sim 50 \%)$ and a permeability reduction of up to one order of magnitude were critical indicators of self-healing success providing enhanced durability recovery. Based on the laboratory work, a dosage of $8 \%$ by volume of the cement was selected for the field trials.

\subsection{Calcite-precipitating bacteria}

The general principle here is that bacteria are encapsulated in the cementitious matrix and, provided that there is an appropriate source of calcium available, they can precipitate calcium carbonate in cracks under favourable conditions. There are a number of key pathways dependent on the bacteria used
(De Belie et al., 2017): (a) enzymatic hydrolysis of urea, (b) dissimilation of nitrates and (c) aerobic metabolic conversion. Research within M4L concentrated on the last approach, in which spores of the bacteria were encapsulated in concrete together with calcium acetate and nutrients at the mixing stage. When cracks occur in the concrete, ingress of water and oxygen then occurs and the spores can germinate and aid the conversion of calcium acetate to calcium carbonate. Carbon dioxide is also released, and this results in further carbonation of hydrates in the locality of the crack, promoting further healing. For self-healing to work, an appropriate non-ureolytic species capable of germinating and precipitating calcium carbonate sufficiently quickly in the alkaline conditions present in concrete is required. Based on literature, three species of bacteria were selected for detailed investigation as described elsewhere (Sharma et al., 2017). This led to the selection of Bacillus pseudofirmus DSM 8715 (Figure 3(a)) for use in further studies. It produces spores readily in short time frames $(24 \mathrm{~h}$ ), and its spores germinate rapidly and achieve almost full germination within $2 \mathrm{~h}$ (Sharma et al., 2017). Further tests showed that the survivability of the spores in cement paste was low and on the order of only $1-4 \%$ after $93 \mathrm{~d}$.

Because problems with survival of the spores may have been a limiting factor, it was considered necessary to take steps to protect the spores in the concrete, and expanded perlite was used for this purpose. The growth medium (calcium acetate and yeast extract) was also encapsulated in expanded perlite, but, unlike other research (De Belie et al., 2018), the spores and growth medium were not encapsulated in the same particles. It was found that self-healing could be observed visually provided that there was an appropriate ratio of spores to growth media (illustrated in Figures 3(b) and 3(c)). Self-healing was quantified by means of a modified initial surface absorption test (bespoke), and it was shown that those specimens in which visual healing could be observed had the lowest initial surface absorption values as expected. Parallel microbiological tests reported by Alazhari et al. (2018) have suggested that it may be possible to achieve greater healing with the use of a multicomponent growth medium consisting of ingredients to promote germination of spores and growth of the bacteria further, although, for the full-scale field

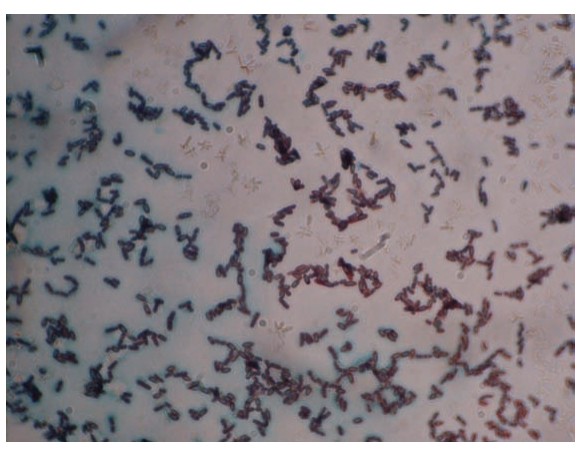

(a)

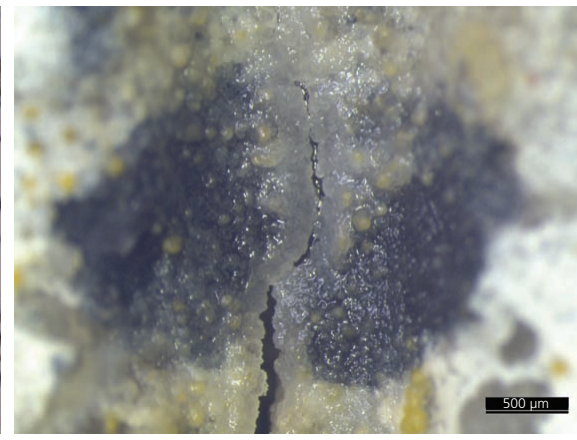

(b)

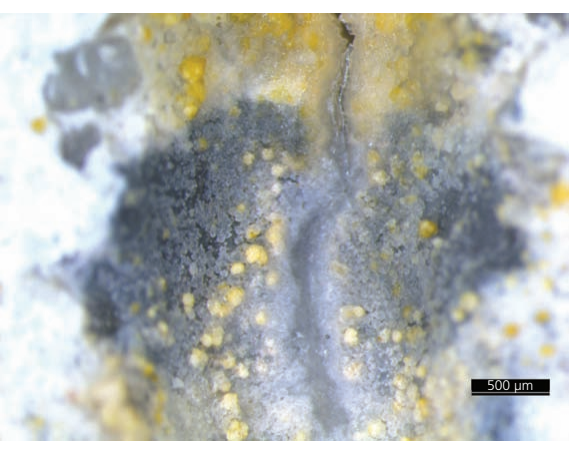

(c)

Figure 3. Bacterial healing: (a) spores of B. pseudofirmus; (b, c) self-healing of a crack by the action of $B$. pseudofirmus 
trials, only yeast extract was utilised as a source of nutrients. Prior to the field trials, the M4L team also undertook further laboratory trials to demonstrate that concrete with encapsulated calciteprecipitating bacteria met appropriate technical specifications for consistency and strength (Paine et al., 2016).

\subsection{Shape memory polymers}

SMPs are materials that respond to external stimuli by altering their physical shape. A novel approach of incorporating heatactivated SMPs into cementitious systems allows postconstruction cracks to be closed. There is also the added benefit that the reduction in the size of the cracks facilitates autogenic self-healing (Isaacs et al., 2013). Thus, these tendons form part of a self-healing system in which the tendons are activated when damage is detected. In M4L, tendons formed from amorphous SMP filaments, formed by die drawing, were heated above their glass transition temperature $\left(T_{\mathrm{g}}\right)$ while restrained. This process generates a restrained shrinkage stress that serves to close cracks. The restrained tendons also apply a small compressive stress across the crack faces, which aids autogenic healing. While earlier studies had demonstrated the feasibility of SMPs using commercially available polyethylene terephthalate (Pet) (Isaacs et al., 2013; Jefferson et al., 2010), findings from the M4L work (Isaacs et al., 2013; Jefferson et al., 2010) showed that SMPs reduce crack widths $(0.5 \mathrm{~mm}$ wide) by an average $74 \%$. This reduction rose to $93 \%$ when specimens were healed in water. In addition to these results, M4L work found that autogenic selfhealing made possible by the autonomic use of SMPs produced a $13 \%$ load recovery (defined as the ratio of the maximum load achieved after healing to the maximum load achieved prior to the creation of the damage) after $28 \mathrm{~d}$ healing, in comparison with $1 \%$ for control specimens. For this technique to be employed in the field, it was necessary to develop a new tendon assembly and a remote activation technique. The technique developed by M4L for this purpose used a tendon comprising multiple $0.9 \mathrm{~mm}$ dia. SMP filaments, an outer spiral wire for electrical activation and a plastic sheath for protection (Figures 4(a) and 4(b)) (Pilegis et al., 2015; Teall et al., 2017). As reported by Teall et al. (2018), these were further tested in $500 \times 100 \times 100 \mathrm{~mm}^{3}$ concrete beams, but this time half of the specimens also included two $6 \mathrm{~mm}$ dia. high tensile ribbed steel bars placed either side of the SMP tendon to replicate the restraint that will be provided by traditional rebar. From this study (Teall et al., 2018), it was concluded that restrained shrinkage stresses of $20 \mathrm{MPa}$ could be generated in the tendon, which resulted in crack closures of up to $85 \%$ and a significant increase in beam stiffness on reloading in unreinforced beams. In contrast, in the reinforced beams, crack closure was only just over $30 \%$, which suggests that a higher shrinkage stress is needed for the system to be truly effective in reinforcedconcrete elements.

\subsection{Vascular networks}

To address the additional challenge of repeat self-healing, M4L research investigated the benefits of incorporating vascular networks in concrete elements to deliver healing agents to cracked regions. These networks comprise connected capillary channels as illustrated in Figures 5(a)-5(c). A new method for creating interconnected channels within a concrete structural element was developed. The method involves placing interconnected polyurethane tubes in a mould or shutter prior to casting and subsequently withdrawing them when the concrete has hardened, thereby leaving a permanent network of channels (or vascular networks) within the body of the concrete member (Davies et al., 2015). This method was shown to be sufficiently robust and scalable to be used on a construction site. To facilitate the use of vascular networks, the M4L team designed and undertook a series of combined numerical-experimental studies to investigate the capillary flow properties of healing agents in concrete cracks. These studies explored the transport behaviour of a range of natural and autonomic agents in manufactured (smooth) and natural (rough) cracks of varying apertures (Gardner et al., 2012, 2014, 2017). This research established a series of parameters that characterise viscous resistance, capillary tension, contact angle, meniscus resistance, stick-slip and wall resistance. In addition, based on these studies, a model that uses the Lucas-Washburn equation for capillary flow for accurately predicting the flow properties of a range of healing agents in cracks was developed and validated by the M4L team (Gardner et al., 2017). Based on the findings of these characterisation studies, cyanoacrylate, commonly known as 'superglue', was chosen for use in the vascular network laboratory tests because of its low viscosity and rapid polymerisation. However, for site trials, for which a longer healing time was preferable, sodium silicate was chosen as the healing agent. The laboratory test series showed that healing agents can be delivered by capillary flow alone but that it is beneficial to apply a small additional pressure to improve healing agent delivery. For this reason, a pressure of $0 \cdot 1$ bar above atmospheric pressure was applied to the healing agent in the site trials.

\section{Field deployment and applications to date}

Findings from the preceding laboratory research to deliver four autonomic self-healing systems (microcapsules, calciteprecipitating bacteria, shape memory tendons and vascular networks) were used to inform the design of full-scale field trials as part of the Welsh government's A465 Heads of the Valleys Highways Upgrade scheme, for which Costain is the main contractor. The purpose of the full-scale field trials was to assess the full-scale application and performance of the developed autonomic self-healing systems in the field.

The field trials involved the construction of five full-scale concrete retaining wall panels, each $1.8 \mathrm{~m}$ high and $1 \mathrm{~m}$ wide (Figure 6) (Davies et al., 2016, 2018; Teall et al., 2016). These reinforcedconcrete panels (henceforth panels) included a control panel and four self-healing panels, in which individual and combinations of the M4L self-healing systems were embedded. The reinforcement was placed (Figure 6(a)) to allow cracking to occur at around $0.5 \mathrm{~m}$ from the base of the wall when loaded as a cantilever. The concrete used throughout was a ready-mix C40/50 concrete, using CEM I and limestone aggregates and with a water-to-cement ratio of $0 \cdot 43$. 

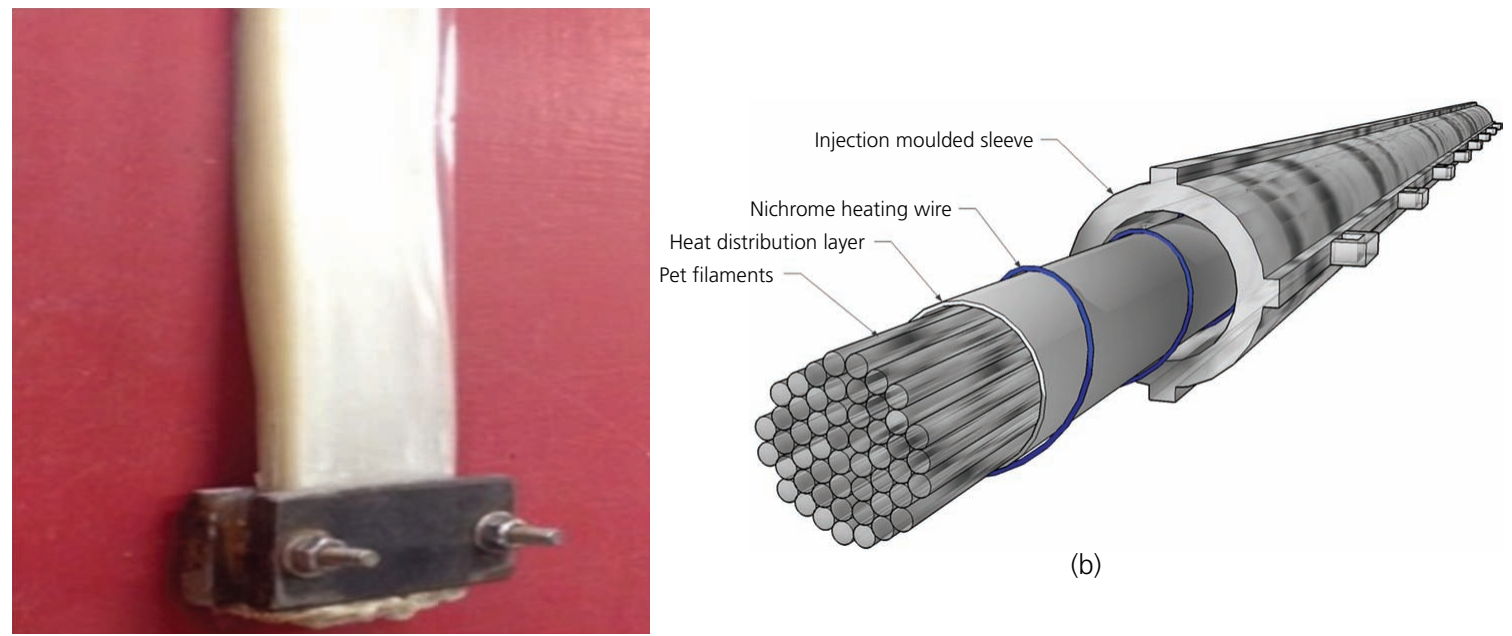

(a)
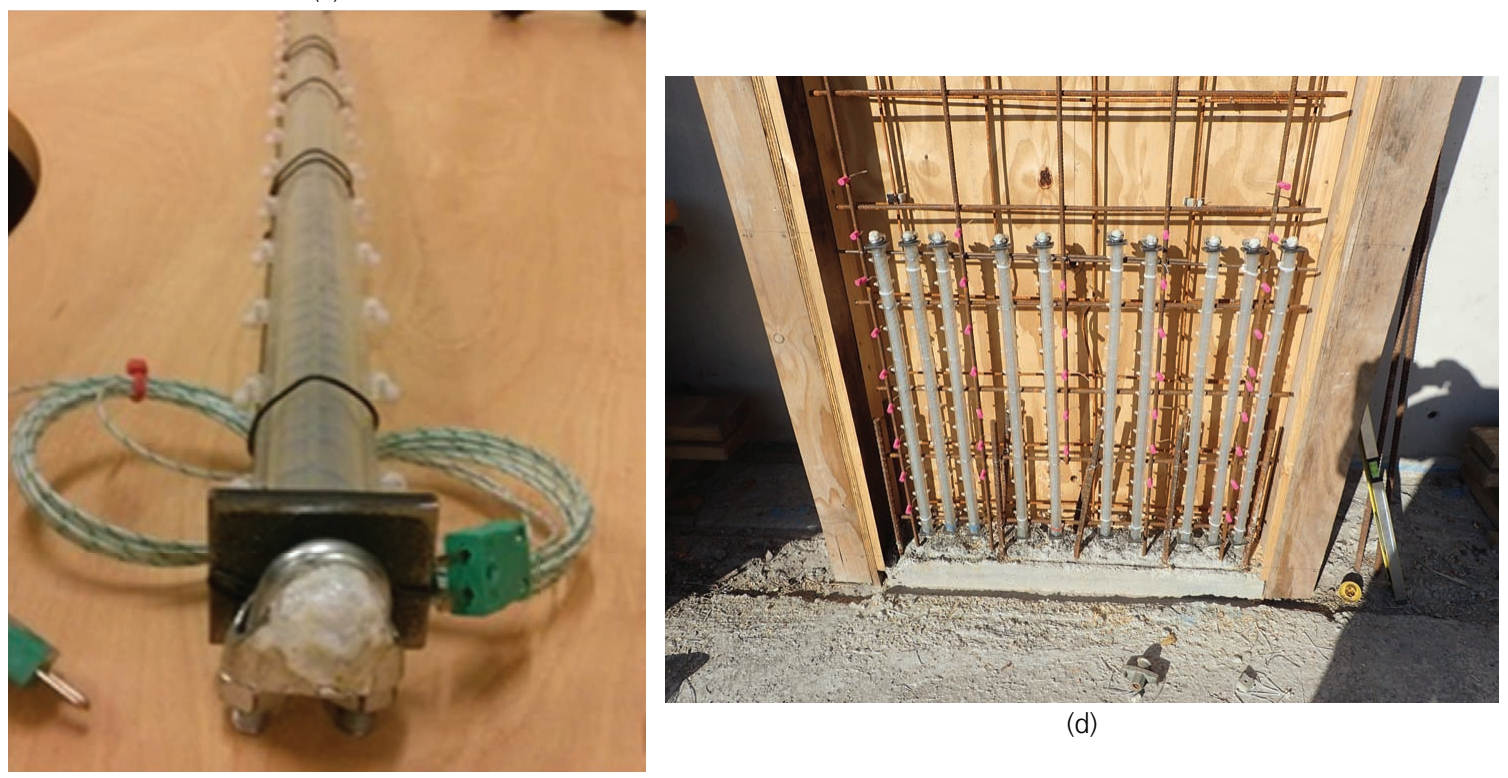

(d)

(c)

Figure 4. SMPs for self-healing: (a) a typical example of an SMP shape (Teall, 2017); (b) SMP (Davies et al., 2018) and (c) tendon assembly developed and tested within cementitious matrices; (d) a section of a wall showing the installed SMP and vascular networks (Davies et al., 2018)

The self-healing systems used in each of the panels are summarised in Table 1. Panels A and $\mathrm{C}$ were used to investigate the influence of microcapsules and bacteria, respectively, on the behaviour of the concrete and their ability to provide autonomic healing when damaged. Panel $\mathrm{B}$ was used to assess the ability of the SMP tendons to both close the cracks that were formed and any subsequent autogenic healing. Panels $\mathrm{D}$ and $\mathrm{E}$ were used as controls to provide a record of the behaviour of a standard reinforced-concrete wall without any additions and one containing an empty embedded flow network. At a later date, the flow networks in panels $\mathrm{B}$ and $\mathrm{E}$ were flushed with a sodium silicate solution to assess the ability of the networks to deliver a healing agent and whether the degree of healing was enhanced by the use of the tendons to close the cracks.
Based on the results from M4L studies on microcapsules, panel A was constructed using a concrete mix with microcapsules at $8 \%$ by volume of cement ( $\sim 2.7 \%$ by weight), which corresponded to $0 \cdot 47 \%$ by weight of the total concrete mix. The microcapsules, supplied in a preserving solution, were first washed with water and filtered before being added, in their slurry form, directly into the concrete mix using a portable 120L Belle concrete mixer. In panel B, vascular networks were combined with SMP tendons. A two-dimensional network of $4 \mathrm{~mm}$ dia. channels was created using polyurethane tubes, which were removed from the concrete after the formwork had been struck. The channels were connected using three-dimensional (3D)-printed joints made from poly(lactic acid), which were tied to the outermost reinforcement. At either side of the panel, the flow networks were terminated with lockable steel injection packers, which allowed each 


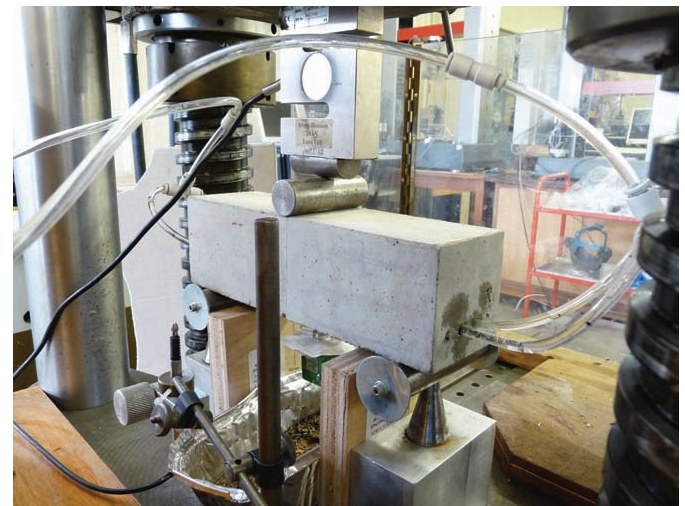

(a)

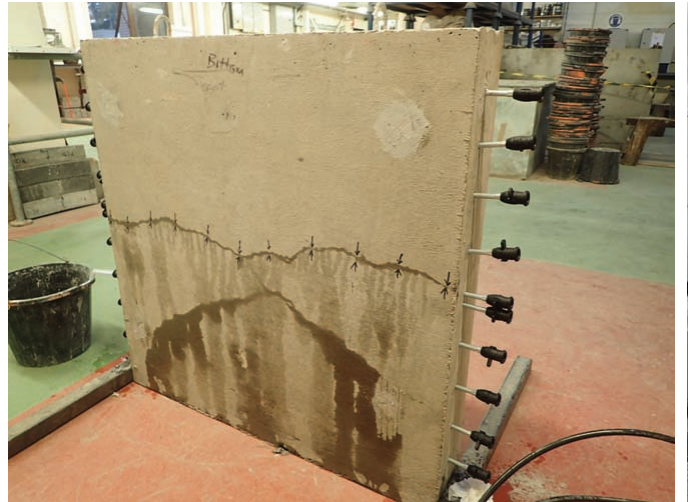

(b)

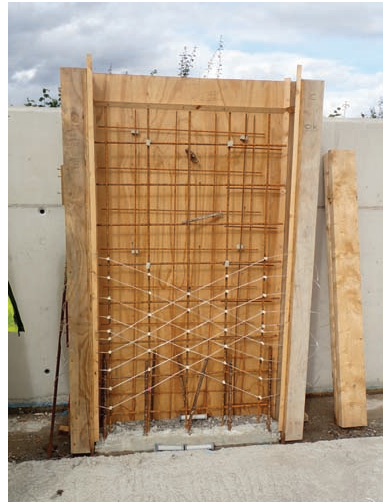

(c)

Figure 5. Vascular networks in (a) laboratory experiments, (b) large-scale laboratory testing and (c) the field trials' wall panel

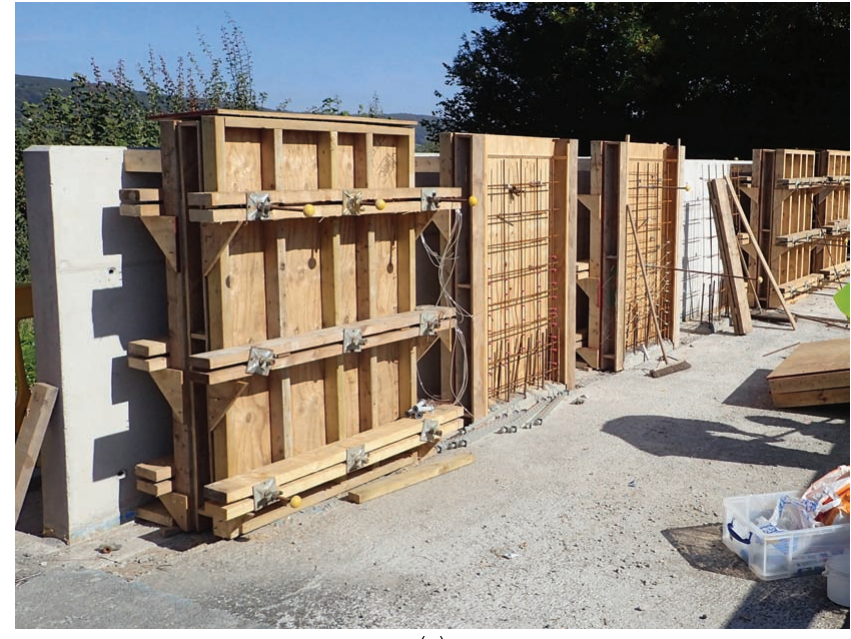

(a)

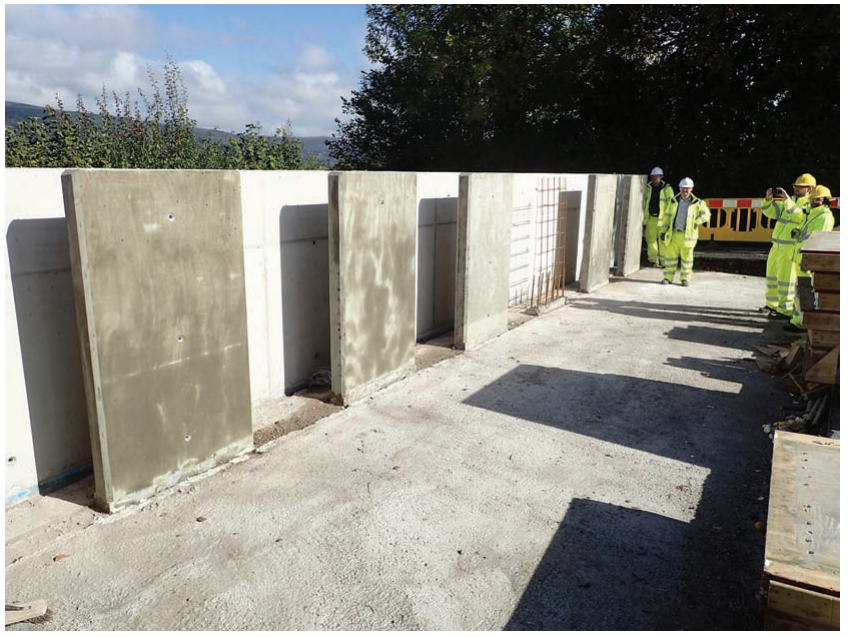

(b)

Figure 6. The M4L field trials of self-healing concrete wall panels at the A465 site (a) during construction and (b) after demoulding. Visible from left to right in both (a) and (b) are panels A, B,C, D and E. Details of self-healing systems are available in Table 1

channel to be sealed individually to aid the loading and pressurising of the network. Sodium silicate solution was pumped through the tubes using a nominal pressure of $0 \cdot 1$ bar. This panel also included ten $750 \mathrm{~mm}$ long SMP tendons, which were designed, upon activation, to generate a stress of $0.5 \mathrm{MPa}$ across the cracked external face. Each tendon contained 200 Pet filaments that were surrounded by a heating system and a 3D-printed polymer sleeve. The Pet

Table 1. Trial panels and their embedded self-healing mechanisms (Davies et al., 2018)

\begin{tabular}{ll} 
Panel & Self-healing system/materials used in the panel \\
\hline A & Microcapsules containing sodium silicate cargo \\
B & SMP tendons and an empty embedded flow network \\
C & Bacteria and nutrient-infused perlite and an empty \\
embedded flow network \\
D & Control \\
E & Control with an empty embedded flow network
\end{tabular}

filaments, manufactured by Bradford University, were capable of generating a restrained shrinkage stress of $30 \mathrm{MPa}$ in the laboratory. These tendons were placed at an eccentricity of $40 \mathrm{~mm}$ in a staggered layout. In panel $\mathrm{C}$, the components for bacterial healing were encapsulated before addition to the concrete mix and only used in the zone surrounding the expected location of the main crack. Coated perlite impregnated with spores was used at a content of $45 \mathrm{~kg} / \mathrm{m}^{3}$, equating to $\sim 4 \times 10^{13}$ spores $/ \mathrm{m}^{3}$ of concrete, while the coated perlite containing nutrients was included at $140 \mathrm{~kg} / \mathrm{m}^{3}$ and provided $3 \cdot 8 \%$ calcium acetate by mass of cement and $0 \cdot 1 \%$ yeast extract by mass of cement to the concrete. In addition, two panels (panels D and E) were cast which acted as controls. One was a standard reinforced-concrete panel, and the second panel had an empty flow network with no healing agent. Both panels were used for comparison purposes.

The panels were constructed in September 2015 and then subjected to damage and allowed to subsequently heal. The damage the panels 
were subjected to was a simulation of that they would experience under normal use. The responses of the panels in both pre- and posthealed conditions were monitored with a range of in situ instrumentation and visualisation techniques. Both the scaling-up process and the field trial applications successfully demonstrated the feasibility of commercial production and application of those selfhealing systems. All self-healing panels exhibited measurable healing responses, in terms of both stiffness/strength recovery and crack filling. The field trials also highlighted a number of challenges and areas for further improvement in the self-healing systems, and further research has been initiated in response to these challenges. Although not all SMP tendons in panel B were successfully activated, an average reduction in crack width of $\sim 20 \%$ and an increase in stiffness upon reloading of the panel were achieved. Furthermore, the vascular network in the same panel was shown by visual surface observations to be able to deliver healing agent to fill cracks but produced only limited mechanical healing. The microcapsule panel (panel A) confirmed the real-time feasibility of microcapsule-based healing, showing improved crack-size reduction (width and depth) of $\sim 60 \%$ as early as 1 month and recovery in permeability (by $\sim 2 \cdot 5$ orders of magnitude) at 6 months of self-healing. While some healing was identified in the section of panel $\mathrm{C}$ that contained the bacteria, the extent of self-healing was less than anticipated. Based on the working hypothesis that the lower than anticipated level of self-healing was caused by cold weather, further work has now been initiated by the research team to identify bacteria more appropriate for use in low temperatures. While it is acknowledged that the field conditions were far more severe than the laboratory-imposed conditions, the results from the field trials are extremely promising.

\section{Discussion}

\subsection{Potential commercial benefits}

There has been significant interest to date from companies across the whole supply chain, contractors, consultants, material suppliers and construction chemical companies, and from client organisations, who have identified practical applications for the four self-healing systems. The huge appetite for self-healing cementitious systems of the construction industry and their potential benefits is captured and documented in market research conducted for M4L by Lychgate in 2016, who surveyed and interviewed over 40 major construction organisations (Gardner et al., 2018). The survey provided evidence of the continuing problems with current cementitious materials in existing and new concrete structures and identified potential applications for self-healing cementitious systems in bridges and highways, marine and water-retaining structures, tunnels (at joints, in sprayed concrete and precast elements), nuclear installations, dams, concrete piles and airport runways. The benefits anticipated by survey respondents include reduced use and costs of overdesign to provide resilience, the need for fewer additives and reduced concrete cover and reinforcement.

The significant advances and recent successes made in the Netherlands on the development of bacteria-based self-healing for concrete (referred to as bioconcrete), currently commercialised through the spin-out company Basilisk, provides confidence in the proposed technologies. Furthermore, the development and commercial application of self-healing asphalt, with induction heating, also in the Netherlands, illustrates the type of benefits that can similarly be realised through the application of the self-healing systems described in this paper to concrete. The first self-healing asphalt road in the Netherlands was constructed in 2010 on a $400 \mathrm{~m}$ stretch on the A58 motorway near Vlissingen and was donated by the government as a test bed. The motorway has been in public use since. This and similar application on 12 other Dutch roads, all of which are in a good condition, have led to conclusions that the life of these asphalt roads can be doubled if they are melted every 4 years and demonstrated that self-healing asphalt could save the Dutch $€ 90$ million/year in routine maintenance costs, if used on all Dutch roads (Interesting Engineering, 2017).

\subsection{Impact on whole-life costs}

The M4L project undertook various cost and economic feasibility analyses and studies. In the Lychgate market research study outlined earlier (Gardner et al., 2018), a 20\% increase in the initial cost was considered acceptable by concrete producers, although it was clear that they would be aiming for a much lower premium. A whole-life costing (WLC) exercise for a bridge deck under construction as part of the A465 Heads of the Valleys road improvement project was carried out as a case study (Teall, 2017). Adaptations were made to deterioration curves in the Structures Asset Management Planning Toolkit to allow self-healing concrete deck slabs to be modelled over varying numbers of self-healing cycles. Comparisons of the costs associated with a conventional reinforced-concrete deck slab against a self-healing concrete deck slab capable of one, two, three and $n$ (indefinite) healing cycles, were performed (Teall, 2017). The results demonstrated that a concrete deck slab capable of only a single healing cycle would not reduce the WLC of the structure. A slab capable of multiple healing cycles could enable a WLC saving of up to $\sim 12 \%$. Given the relatively low material cost of the concrete deck slab compared to the potential savings over the 120-year study period, this finding means an increase in material cost of up to 20 times could be justified for the use of a self-healing concrete capable of multiple healing cycles. A sensitivity analysis also highlighted that a self-healing concrete deck slab is most viable for structures subject to severe exposure conditions.

\subsection{Main challenges and barriers}

The main challenges and barriers which need to be addressed to enable the maximum uptake of the technology are the same as those associated with the introduction of any new construction materials. Specifically, these self-healing concrete technologies include the need for $(a)$ extensive validation data to provide confidence, (b) material certification to prove compliance with national and international standards, (c) design procedures and analysis methods to be developed before the proposed systems can be safely applied, (d) appropriate development and exploitation costs to ensure commercial viability and (e) approaches for addressing the risk averse nature of the construction industry by ideally entering the construction market through, say, the repair 
Smart Infrastructure and Construction

Volume 171 Issue SC2
Biomimetic cementitious construction

materials for next-generation

infrastructure

Al-Tabbaa, Lark, Paine et al. market to provide evidence of performance. It is also important to recognise that the implementation of self-healing construction materials may create a paradigm change in the way that infrastructure is designed and its performance is evaluated. This is also an opportunity as much as a barrier.

\section{The next stage}

The promising results from the M4L research on developing selfhealing cementitious systems have led to the strategic funding of the much larger research project Resilient Materials for Life (RM4L). While the M4L research reported here was focused specifically on the development of self-healing systems that respond to a physical damage in the form of crack, RM4L, in the next phase of research, has a broader remit focused on tailoring self-healing cementitious systems use in specific commercial applications and on addressing different damage scenarios and conditions. Applications of commercial interest, have been identified through market research (Gardner et al., 2018) and include casting in situ, precast sections, repair, overlays and geotechnical applications. Additionally, important damage scenarios have been identified and include time-related and cyclic damage and chemical damage including corrosion. In addition to self-healing attributes, RM4L will initiate groundbreaking research aimed at embedding self-sensing, self-diagnosing, self-immunisation and self-reporting capabilities into cementitious systems in order to develop truly biomimetic responses in infrastructure materials and structures. Furthermore, RM4L will work closely with industry partners to address challenges associated with the upscaling of the self-healing systems and their introduction to the market. Both numerical modelling and experimental work will be used in the optimisation and tailoring aspects. For more details about the scope and focus of RM4L, see their website (RM4L, 2018).

\section{Conclusions}

This paper advocates that those who design and construct the next generation of infrastructure should embrace and use biomimetic cementitious construction materials. This is the mission that the authors and their teams and wider academic and industry partners set themselves when initiating M4L over 4 years ago, and on which they will be engaged for the next 4 years, through RM4L. Through M4L's research, a number of complementary self-healing systems for cementitious matrices have been successfully developed. These include $(a)$ microcapsules with switchable mechanical properties and with mineral healing cargo; $(b)$ bespoke combinations and microencapsulation of alkaliphilic bacteria, nutrients and precursors for rapid precipitation of healing products; $(c)$ innovatively created vascular network using polyurethane tubing; and $(d)$ remotely activated SMP multistrand sheathed tendons. Full-scale field trials were undertaken in 2015 to validate the scaling up of the developed systems and their success at delivering self-healing at full scale. There is a significant level of ongoing interest from the industry in taking forward these developments, and associated market research has identified the benefits of self-healing cementitious systems. Cost and economic viability studies provide assurances of whole-life costeffectiveness of these systems. The work has also identified a number of challenges and barriers, and the next 4 years of research and development will see this national initiative expanded to a completely different level of complexity, breadth and practical application.

\section{Acknowledgements}

Financial support from the UK Engineering and Physical Sciences Research Council for the Materials for Life grant (EP/K026631/1, 2013-2016) and the programme grant Resilient Materials for Life $(\mathrm{EP} / 02081 \mathrm{X} / 1$, 2017-2022) is gratefully acknowledged. The contribution of the rest of the research team and all the industry partners involved is also gratefully acknowledged.

\section{REFERENCES}

Alazhari M, Sharma T, Heath A, Cooper R and Paine K (2018) Application of expanded perlite encapsulated bacteria and growth media for selfhealing concrete. Construction and Building Materials 160: 610-619, https://doi.org/10.1016/j.conbuildmat.2017.11.086.

Al-Tabbaa A, Lark R, Paine K, Jefferson T and Embley T (2017) Smart biomimetic construction materials for next generation infrastructure. Proceedings of ISNGI 2017, London, UK, pp. 1-10.

Davies RE, Jefferson A and Lark Rand Gardner D (2015) A novel 2D vascular network in cementitious materials. Proceedings of $2015 \mathrm{fib}$ Symposium, Copenhagen, Denmark.

Davies R, Pilegis M, Kanellopoulos A et al. (2016) Multi-scale cementitious self-healing systems and their application in concrete structures. Proceedings of the 9th International Concrete Conference 2016 - Environment, Efficiency and Economic Challenges for Concrete, Dundee, UK

Davies R, Teall O, Pilegis M et al. (2018) Large scale application of selfhealing concrete: design, construction and testing. Frontiers in Materials 5: 51, https://doi.org/10.3389/fmats.2018.00051.

De Belie N, Wang J, Bundur ZB and Paine K (2017) Bacteria based concrete. In Eco-efficient Repair and Rehabilitation of Concrete Infrastructures (Pacheco-Torgal F, Melchers R, de Belie N et al. (eds)). Woodhead, Cambridge, UK, pp. 531-567.

De Belie N, Gruyaert E, Al-Tabbaa A et al. (2018) A review of self-healing concrete for damage management of structures. Advanced Materials Interfaces 5(17): 1800074, https://doi.org/10.1002/admi.201800074.

de Rooij M, Van Tittelboom K, De Belie N and Schlangen E (eds) (2013) Self-healing Phenomena in Cement-based Materials: State-of-the-art Report of RILEM Technical Committee 221-SHC. Springer, Dordrecht, the Netherlands.

EC (European Commission) (2014) Business Innovation Observatory Smart Living: Advanced Building Materials. EC, Brussels, Belgium.

Ferrara L, Van Mullem T, Alonso MC et al. (2018) Experimental characterization of the self-healing capacity of cement based materials and its effects on the material performance: a state of the art report by COST Action SARCOS WG2. Construction and Building Materials 167: 115-142, https://doi.org/10.1016/j.conbuildmat.2018.01.143.

Gardner D, Jefferson A and Hoffman A (2012) Investigation of capillary flow in discrete cracks in cementitious materials. Cement and Concrete Research 42(7): 972-981, https://doi.org/10.1016/j.cemconres.2012.03. 017.

Gardner D, Jefferson A, Hoffman A and Lark A (2014) Simulation of the capillary flow of an autonomic healing agent in discrete cracks in cementitious materials. Cement and Concrete Research 58: 35-44, https://doi.org/10.1016/j.cemconres.2014.01.005.

Gardner D, Herbert D, Jayaprakash M, Jefferson A and Paul A (2017) Capillary flow characteristics of an autogenic and autonomic healing agent for self-healing concrete. Journal of Materials in Civil Engineering 29(11): 04017228, https://doi.org/10.1061/\%28ASCE\% 29MT.1943-5533.0002092.

Gardner D, Lark R, Jefferson T and Davies R (2018) A survey on problems encountered in current concrete construction and the potential benefits 
of self-healing cementitious materials. Case Studies in Construction Materials 8: 238-247, https://doi.org/10.1016/J.CSCM.2018.02.002.

Giannaros P (2017) Laboratory and Field Investigation of the Performance of Novel Microcapsule-based Self-healing Concrete. $\mathrm{PhD}$ thesis, University of Cambridge, Cambridge, UK.

Giannaros P, Kanellopoulos A and Al-Tabbaa A (2016) Damage recovery in self-healing concrete. Proceedings of HealCon Conference, Delft, the Netherlands.

GO-Science (Government Office for Science) (2017) Technology and Innovation Futures. GO-Science, London, UK.

HMT (Her Majesty's Treasury) (2016) National Infrastructure Delivery Plan 2016-2021. HMT, London, UK. See http://www.gov.uk/ government/publications (accessed 31/10/2018).

i3P (Infrastructure Industry Innovation Platform) (2017) Technology Roadmap for UK Construction \& National Infrastructure. i3P, UK. See https://www.i3p.org.uk/wp-content/uploads/2017/07/i3P-CITechnology-Roadmap-Booklet-FINAL.pdf (accessed 31/10/2018). Interesting Engineering (2017) Simple Self-healing Roads Can Last up to 80 Years. Interesting Engineering, Istanbul, Turkey. See https:// interestingengineering.com/self-healing-roads-last-80-years (accessed 31/10/2018).

Isaacs B, Lark R, Jefferson T, Davies R and Dunn S (2013) Crack healing of cementitious materials using shrinkable polymer tendons. Structural Concrete 14(2): 138-147, https://doi.org/10.1002/suco. 201200013.

Jefferson A, Joseph C, Lark R et al. (2010) A new system for crack closure of cementitious materials using shrinkable polymers. Cement and Concrete Research 40(5): 795-801, https://doi.org/10.1016/j. cemconres.2010.01.004.

Kanellopoulos A, Qureshi TS and Al-Tabbaa A (2015) Glass encapsulated minerals for self-healing in cement based composites. Construction and Building Materials 98: 780-791, https://doi.org/10.1016/j. conbuildmat.2015.08.127.

Kanellopoulos A, Giannaros P and Al-Tabbaa A (2016) The effect of varying volume fraction of microcapsules on fresh, mechanical and self-healing properties of mortars. Construction and Building Materials 122: 577-593, https://doi.org/10.1016/j.conbuildmat.2016. 06.119.

Kanellopoulos A, Giannaros P, Palmer D, Kerr A and Al-Tabbaa A (2017) Polymeric microcapsules with switchable mechanical properties for self-healing concrete: synthesis, characterisation and proof of concept. Smart Materials and Structures 26(4): 045025, https://doi.org/10.1088/ 1361-665X/aa516c

Kelly S (2014) The cost of cascading failure: risk and resilience within UK infrastructure networks. Proceedings of the Future of National Infrastructure Systems \& Economic Prosperity Conference, Cambridge, UK.

Lark RJ, Al-Tabbaa A and Paine K (2013) Biomimetic multi-scale damage immunity for construction materials: M4L Project overview.

Proceedings of 4th International conference on Self-healing Materials, Ghent, Belgium, pp. 2-5.

Litina C (2015) Development and Performance of Self-healing Blended Cement Grouts with Microencapsulated mineral Agents. PhD thesis, University of Cambridge, Cambridge, UK.

ONS (Office for National Statistics) (2016) Construction Output in Great Britain: May 2016. ONS, Newport, UK. See https://www.ons.gov.uk/ (accessed 31/10/2018).

Paine K, Lark R and Al-Tabbaa A (2015) Biomimetic multi-scale damage immunity for concrete. Concrete Research: Driving Profit and Sustainability, Jalandhar, India

Paine K, Alazhari M, Sharma T, Cooper R and Heath A (2016) Design and performance of bacteria-based self-healing concrete. Proceedings of the 9th International Concrete Conference 2016: Environment, Efficiency and Economic Challenges for Concrete, Dundee, UK, pp. $545-554$
Pilegis M, Teall O, Hazelwood T et al. (2015) Delayed concrete prestressing with shape memory polymer tendons. Concrete Innovation and Design, fib Symposium, Copenhagen, Denmark.

Qureshi TS (2016) The Role of Expansive Minerals in the Autogenous and Autonomic Self-healing of Cement Based Materials. PhD thesis, University of Cambridge, Cambridge, UK.

RM4L (Resilient Materials 4 Life) (2018) http://rm4l.com/about/ (accessed 31/10/2018).

Sharma TK, Alazhari M, Heath A, Paine K and Cooper RM (2017) Alkaliphilic Bacillus species show potential application in concrete crack repair by virtue of rapid spore production and germination then extracellular calcite formation. Journal of Applied Microbiology 122(5): 1233-1244, https://doi.org/10.1111/jam.13421.

Souza LR (2017) Polymeric Microcapsules Using Microfluidics for Selfhealing in Construction Materials. PhD thesis, University of Cambridge, Cambridge, UK.

Teall O (2017) Crack Closure and Enhanced Autogenous Healing of Structural Concrete Using Shape Memory Polymers. PhD Thesis, Cardiff University, UK.

Teall O, Davies R, Pilegis M et al. (2016) Self-healing concrete full-scale site trials. In Proceedings of the 11th fib International PhD Symposium in Civil Engineering, FIB 2016 (Maekawa K, Kasuga A and Yamazaki J (eds)). Balkema, Rotterdam, the Netherlands, pp. 639-646.

Teall O, Pilegis M and Davies R (2017) Development of high shrinkage polyethylene terephthalate (Pet) shape memory polymer tendons for concrete crack closure. Smart Materials and Structures 26(4): 045006, https://doi.org/10.1088/1361-665X/aa5d66.

Teall O, Pilegis M, Davies R et al. (2018) A shape memory polymer concrete crack closure system activated by electrical current. Smart Materials and Structures 27(7): 075016, https://doi.org/10.1088/1361$665 X / a a c 28 a$.

Tilly G and Jacobs J (2007) Concrete Repairs: Performance in Service and Current Practice. BRE Press, Bracknell, UK.

WEF (World Economic Forum) and BCG (The Boston Consulting Group) (2016) Shaping the Future of Construction: a Breakthrough in Mindset and Technology. WEF, Cologny, Switzerland.

\section{How can you contribute?}

To discuss this paper, please email up to 500 words to the editor at journals@ice.org.uk. Your contribution will be forwarded to the author(s) for a reply and, if considered appropriate by the editorial board, it will be published as discussion in a future issue of the journal.

Proceedings journals rely entirely on contributions from the civil engineering profession (and allied disciplines). Information about how to submit your paper online is available at www.icevirtuallibrary.com/page/authors, where you will also find detailed author guidelines. 